\title{
Cross-Cultural Models in International Advertising and Consumer Behavior Research
}

\author{
Syed Hassan Raza ${ }^{1, *}$, Bahtiar Mohamad ${ }^{2}$, Diah Kristina ${ }^{3}$ \\ ${ }^{I}$ Department of Communication Studies, Bahauddin Zakariya University, Multan, Pakistan \\ ${ }^{2}$ Othman Yeop Abdullah Graduate School of Business, Universiti Utara Malaysia, Malaysia \\ ${ }^{3}$ University Centre of Excellence Javanology for Javanese Traditions, Universitas Sebelas Maret, Surakarta, \\ Indonesia \\ *Corresponding author. Email: sherazibzu@gmail.com
}

\begin{abstract}
Past advertising and marketing research has employed two distinct approaches to understanding consumer behavior. Some studies have used the informational social influence approach by operationalizing the consumer behavior outcome domain as a psychological phenomenon wherein individuals are intended to adopt the actions of others to replicate the accurate behavior in a specified condition. This is contrasted with the cultural approach that advocates normative influence where an individual conforms to be adored or accepted by others. This study is inclined to shed light on the cultural approach wherein conformity is an influence involving a change in consumer behavior to align with normative standards. It is also a common and pervasive approach to define the domains of cross-cultural advertising studies wherein norm-congruence is used in defining the influences on consumption patterns. For a better description, in the case of cultural values incongruence, an individual is persuaded to do somewhat that they might not intend to do but which they distinguish as "necessary" to retain a positive relationship with his/her associated members of a particular group or culture. Thus, the conformity approach generally consequences from identification with the group associates or from compliance of some associates to appease others. The study offered a direction for future international advertising research to tap the cultural influences by using GLOBE dimensions.
\end{abstract}

Keywords: Advertising, Culture, Consumer behavior, GLOBE Cultural dimensions, Marketing

\section{INTRODUCTION}

In the 20th century, global marketers and researchers intensively focused on resemblances of consumers across borders and argued that globalization primes the convergence of consumer behavior based on rationality [1]. Scholars largely assume this convergence leads to standardized consumer desires, sensitivities, and perceptions[2]. For instance, crosscultural reach and acceptance of the products such as $\mathrm{KFC}$, are the success of such global convergence and international advertising have reinforced the concept of a "global culture," that is, the concept that consumers keep analogous values, irrespective of their nation of origin [3][4]. In the 21st century, effective advertising will need to understand the distinctiveness of consumers across cultures. Until recently the influence of culture was not well understood [5]. Overlooking culture's impact has led several corporations to integrate marketing, which instead of growing effectiveness caused in lessening success. Several huge international companies have seen a descent in their revenues because of such cohesive marketing strategies dearth native cultural understanding [6]. For illustration, shrinking lucrativeness headed firms to manifest native cultural norms in their international marketing operations. Empirical research using cultural dimensions is also obvious that instead of standardized practices understanding the local culture sensitivity had become undeniably vital to success [7], [8]. The cultural dimensions proposed by the cultural outline of the GLOBE project are designed to be a sign of the practices and morals at the societal level [9][10]. Consequently, these dimensions may enhance the opportunity to understand the effects of the cultural variations in the discipline of advertising and its connection with consumer behavior[11]. That is how cultural values effects vary across cultures on the decision of the individuals to adopt desired intent as a 
proclaim in the advertising which can be studied for the further cultural explanation of its relationship with the consumer behavior.

Recent advertising research proposes an urgent need to understand the societal, cultural effects on advertising by considering the framework of the GLOBE in the context of advertising[12]. Therefore, it is important to understand the process of moderation of variation of the cultural values by having an empirical study based on the framework of the GLOBE cultural dimensions to explain its effects on the individual's cultural preferences of towards the behavioral outcome as it is notable that limited attention paid to this issue in the literature and remains minimal to explain the link of advertising with the said process [13]. However, not many studies are found in the literature to determine the influence of the cultural norms with the framework of GLOBE dimensions in explaining the vibrant relationship of advertising and consumer behavior in the culture variation perspectives [14]. Thus, it also helps to explicitly the complexity of cultural norms as a factor of influence on the process of consumer behavior formulation stimulated by the advertising within the framework of the GLOBE.

\section{REVIEW OF LITERATURE}

\subsection{Advertising outcome and role of Culture}

There is a substantial body of literature that addresses the advertisement influence on consumer behavior and is explained in several marketing theories[15], [16]. For example, studies indicate that when the verbal and visual cues in the advertisement were used, participants' intentions were altered in a positive direction [17]. Despite, these interesting findings, the marketing models remain detached from the cultural explanations. Steam of literature affirmed that an individual's perceptions of the advertising message must be consistent with their perceptions of their cultural norms to result in a positive intention[18], [19]. However, the notion of the norm in several marketing theories such as the theory of planned behavior TPB refers to the pressure that individual perceive from important others (i.e. peers) to perform, or not to perform but, consistently it emerges as the weakest predictor of intentions[20]. The most likely explanation for inadequate performance of the norm lies in its measurement and in assuming that the effect of cultural influences is mediated by the norms[20][4].

A similar measurement issue can be observed in advertising research, past studies have used individual-level measures such as Hofstede dimensions in deciphering advertising effects based on the individual's perception of their cultural norms[4].
Scholars have criticized the Hofstede dimensions, that these dimensions lack the currency and fine grain essential to commendably forecast the success of the numerous advertising appeals at the societal level[21], [22]. Further, this interaction between individual perceptions of the advertisement content and individual perceptions of societal norms remains largely inconclusive because of inconsistent and contradictory findings [8].

To address this, issue scholars [23] [7] recommended that there are two aspects of values that must be considered in cultural research. Are values conceptions of the desirable (norms) or the desired? "What GLOBE calls values are in fact norms that reflect the desirable" [7] pp. 647. Researchers have mentioned that the appropriate way to measure cultural influence is by asking individuals to report their accepted values and behavior of other individuals of their society which are referred to cultural norms (e, g., GLOBE dimensions), instead of aggregating personal values (e.g., Hofstede dimensions)[24].

\subsection{GLOBE Framework a way forward}

To this point, scholars have determined that culture affects values and norms and consequent behavior[25]. To comprehend culture's effects, researchers have characterized several sets of cultural dimensions and distinguished different societies along those dimensions by numerous models, for example, the Hofstede dimensions, cultural theory by Schwartz, and the GLOBE dimensions[26][9]. Albeit, Hofstede's dimensions have been applied in most advertising studies to evaluate the cultural influences[7]. But recent studies have identified the GLOBE model as a more comprehensive model to be used in advertising research[7].

However, there are several reasons to use the cultural dimensions of the GLOBE framework to find the empirical significance of the interaction of the cultural norms in the relation of the intention to use a global brand with the advertising appeal. Firstly, the cultural dimensions proposed by the cultural outline of the GLOBE framework reflect the individual's practices and values at the societal level[7]. Scholars mentioned that these dimensions provide the opportunity to understand the effects of the cultural influences to determine the behavioral pattern[27]. Previous literature has revealed that different cultural values and their hierarchies are connected to a diversity of behaviors, for instance, choice of a consumer purchase[11]. Therefore, GLOBE dimensions may be used to understand that how cultural norms affect varies in different nations in making intentional preferences in response to the advertising appeal. 
The study argues that using nine dimensions may give a detailed insight into each dimension, alongside the overall cultural norms congruence influence based on the advertising appeal evaluation by an individual[24]. By doing so, it may give a further cultural explanation of advertising appeal-intention relationship in the context of global brand and to the re-examined influence of the cultural values or norm in the marketing theories. The literature identified that there is needed to re-address the measurement concerns of cultural norms by considering comprehensive construct to fully understand the prediction of behavioral outcomes[20].

Furthermore, the consideration of the GLOBE dimensions to measure how individuals deciphering advertising meanings by using their cultural context and influence consumer behavior [28] [29]. This view is contingent on the cultural dimension's framework of the GLOBE which argues that value and practicebased cultural framework has been accepted to measure deciphering culture. The study agreed with this approach and used the GLOBE dimensions and suggested that future studies may design to capture the cultural influences on the behavioral practices. The theoretical justification for the investigation of cultural norms across cultures is that all members of the society use similar learned norms while interpreting the advertising appeals. Previous literature on culture and its impact on behavior also show two significant positive expectations by considering GLOBE dimensions which support this idea. Firstly, the research argued that measuring the individual's value is a rigorous way to measure cultural influences which are deeply rooted in conventional wisdom to measure the collective culture by considering the individual's value[23]. This is known as the ecological value assumption, which suggests that that knowing the individuals' cultural values is an adequate method of knowing any culture. However, recent studies on the culture disapproved of this conventional approach and recommended that measuring culture by only knowing about the individuals' preferences and then aggregating the outcomes at the cultural level, is only knowing their values[22].

The positive facade of the GLOBE framework is that it has re-operationalized the ecological assumption and verified the onion assumption[22][7]. It allows measuring both values and practices of the individuals. It provides the comprehensive constructs to measure the knowing the individual's desirable in their societies, therefore, better behavioral validity can be expected by using the GLOBE framework. Secondly, the GLOBE dimensions have lesser generalizability issues than previous frameworks like Hofstede. Therefore, we suggest that the association between norms and consumer behavior to respond to any stimuli such as advertising appeal can be generalized as the behaviors of all individuals of any culture by using GLOBE framework.

Consequently, the cultural norms formulate the consumer behavior therefore, it varies culturally. In verily, consumer behavior and cultural norms interactions must be addressed by tapping the culture with appropriate measurements such as proposed in GLOBE. Therefore, the literature suggested that having an intensive study that considers all the dimensions of the culture can provide better implications of the culture. Quite a few studies have applied the GLOBE framework in advertising literature and remained limited to one or two dimensions to explain the interaction of the cultural congruence to predict the intention. For instance, one study found that the inclusion of the performance orientation dimension in advertising can positively influence the evaluation of ads[6]. Similarly, scholars have studied the GLOBE dimension of assertiveness in context of the international advertising[28]. Further, some studies have used GLOBE dimensions in content analysis of advertisements [9]. To date, only eight empirical studies have investigated GLOBE dimensions. In these studies, six dimensions have been studies, three dimensions have never been studied. Further, there is only one study that has examined two dimensions in the framework. Thus, none of the past empirical studies to our knowledge have measured all GLOBE dimensions. Therefore, we urge the researcher to apply this useful model by applying all nine in a study and examined the generalizability of the GLOBE dimensions.

\section{CONCLUSION}

Norms outline the individual's behavioral practices. Individuals of a particular culture share many commonalities, similar experiences and are socialized to acclimatize to these shared cultural norms. Given that advertising often appeals to consumer's aspirations, it is important to consider the norms associated with societal culture dimensions in advertising communication. The concept of advertising appeals is extended to understand clearly that how cultural elements play a role indefinite the advertising appeals value. Past research has looked much into the functional and emotional consequences related to advertising, but much has yet to be understood how culture comes into play[24]. Thus, future studies can use the theoretical conceptualization of the GLOBE framework and can also manifest them into the advertising appeals to find out how do the cultural elements projected in the advertising appeals can influence consumer behavior. Further, drawing cultural constructs based on the GLOBE model and testing all dimensions can also provide the interaction 
of the norm congruence and consumer behavior in several contexts. For example, some researchers have underpinned the performance orientation to find out the interaction of cultural dimensions with sustainable behavior. This can be a useful strategy in determining the role of local sensitivities in diverse situational factors that consumers can encounter.

\section{AUTHORS' CONTRIBUTIONS}

All authors contribute to the content of the paper from the beginning to the end of writing the paper.

\section{REFERENCES}

[1] C.J. Torelli and R. Ahluwalia, "Extending Culturally Symbolic Brands: A Blessing or a Curse?," J. Consum. Res., vol. 38, no. 5, pp. 933-947, Feb. 2012, doi: 10.1086/661081.

[2] S. Koslow and C. Costley, "How consumer heterogeneity muddles the international advertising debate," Int. J. Advert., vol. 29, no. 2, pp. 221-244, Jan. 2010, doi: $10.2501 / \mathrm{S} 0265048710201130$.

[3] S.A. Westjohn, N. Singh, and P. Magnusson, "Responsiveness to Global and Local Consumer Culture Positioning: A Personality and Collective Identity Perspective," J. Int. Mark., vol. 20, no. 1, pp. 58-73, 2012.

[4] S.H. Raza, H. Abu Bakar, and B. Mohamad, "The effects of advertising appeals on consumers' behavioral intention towards global brands," J. Islam. Mark., vol. 11, no. 2, pp. 440-460, May 2019, doi: 10.1108/JIMA11-2017-0134.

[5] W.T. Neese and J.J. Haynie, "The Influence of Comparative Advertising on Consumer Ethnocentrism in the American Automobile Market," J. Mark. Theory Pract., vol. 23, no. 3, pp. 321-337, Jul. 2015, doi: 10.1080/10696679.2015.1032333.

[6] S.H. Raza, U. Zaman, M. Iftikhar, and O. Shafique, "An Experimental Evidence on EcoFriendly Advertisement Appeals and Intention to Use Bio-Nanomaterial Plastics: Institutional Collectivism and Performance Orientation as Moderators," Int. J. Environ. Res. Public Health, vol. 18, no. 2, p. 791, Jan. 2021, doi: 10.3390/ijerph18020791.

[7] M. de Mooij, "Cross-cultural research in international marketing: clearing up some of the confusion," Int. Mark. Rev., vol. 32, no. 6, pp. 646-662, 2015, doi: 10.1108/IMR-12-
2014-0376.

[8] J. Hornikx and E. de Groot, "Cultural values adapted to individualism-collectivism in advertising in Western Europe: An experimental and meta-analytical approach," Int. Commun. Gaz., vol. 79, no. 3, pp. 298316, Apr. 2017, doi: $10.1177 / 1748048516689180$.

[9] B. Czarnecka, R. Brennan, and S. Keles, "Cultural Meaning, Advertising, and National Culture: A Four-Country Study," J. Glob. Mark., vol. 31, no. 1, pp. 4-17, Jan. 2018, doi: 10.1080/08911762.2017.1376364.

[10] R.J. House, N.R. Quigley, and M. S. de Luque, "Insights from Project GLOBE," Int. J. Advert., vol. 29, no. 1, pp. 111-139, Jan. 2010, doi: $10.2501 / \mathrm{S} 0265048709201051$.

[11] H. Nguyen, "Advertising Appeals and Cultural Values in Social Media Commercials in UK, Brasil and India: Case Study of Nokia and Samsung," Int. J. Soc. Behav. Educ. Econ. Bus. Ind. Eng., vol. 8, no. 8, pp. 2406-2414, 2014, [Online]. Available: http://www.waset.org/publications/9998960.

[12] S. Diehl, R. Terlutter, and B. Mueller, "Doing good matters to consumers: the effectiveness of humane-oriented CSR appeals in crosscultural standardized advertising campaigns," Int. J. Advert., vol. 35, no. 4, pp. 730-757, Jul. 2016, doi: 10.1080/02650487.2015.1077606.

[13] M. Pagani, R. Goldsmith, and A. Perracchio, "Standardization vs. adaptation: consumer reaction to TV ads containing subtitled or English dubbed ads," Int. J. Advert., vol. 34, no. 4, pp. 702-714, Aug. 2015, doi: 10.1080/02650487.2015.1009349.

[14] K. Leung and M.W. Morris, "Values, schemas, and norms in the culture-behavior nexus: A situated dynamics framework," $J$. Int. Bus. Stud., vol. 46, no. 9, pp. 1028-1050, Dec. 2015, doi: 10.1057/jibs.2014.66.

[15] W. Shen et al., "The impact of advertising creativity, warning-based appeals and green dispositions on the attentional effectiveness of environmental advertisements," J. Clean. Prod., vol. 271, p. 122618, Oct. 2020, doi: 10.1016/j.jclepro.2020.122618.

[16] M. Ganjoo, "Influence of advertising appeals on buying behavior with reference to cosmetic brands," Int. J. Psychosoc. Rehabil., vol. 24, no. 8, pp. 8222-8229, 2020. 
[17] L. Teng, N. Ye, Y. Yu, and X. Wu, "Effects of culturally verbal and visual congruency/incongruency across cultures in a competitive advertising context," J. Bus. Res., vol. 67, no. 3, pp. 288-294, Mar. 2014, doi: 10.1016/j.jbusres.2013.05.015.

[18] J. Scanlon, "What It Means to Teach Consumer Culture Remotely Through a Pandemic," Advert. Soc. Q., vol. 21, no. 2, 2020, doi: 10.1353/asr.2020.0013.

[19] S.H. Raza, U. Zaman, and M. Iftikhar, "Examining the Effects of Media-Generated Stereotypes on Receivers' Trust and Attitude in Pakistan. Moderating Influence of Ethnicity and Gender," Inf. 2021, Vol. 12, Page 35, vol. 12, no. 1, p. 35, Jan. 2021, doi: 10.3390/INFO12010035.

[20] F.F. Sniehotta, J. Presseau, and V. AraújoSoares, "Time to retire the theory of planned behavior," Health Psychol. Rev., vol. 8, no. 1, pp. 1-7, 2014.

[21] M. de Mooij, "On the misuse and misinterpretation of dimensions of national culture," Int. Mark. Rev., vol. 30, no. 3, pp. 253-261, 2013, doi: $10.1108 / 02651331311321990$.

[22] P. Brewer and S. Venaik, "The ecological fallacy in national culture research," Organ. Stud., vol. 35, pp. 1-24, 2014, [Online]. Available:

http://oss.sagepub.com/cgi/doi/10.1177/0170 840613517602 .

[23] M. Minkov and V. Blagoev, "What do Project GLOBE's cultural dimensions reflect? An empirical perspective," Asia Pacific Bus. Rev., vol. 18, no. 1, pp. 27-43, 2012.

[24] S. Saleem, "Cultural Paradox in Advertising: Evidence from Finland," J. Promot. Manag., vol. 23, no. 5, pp. 615-632, 2017, doi: 10.1080/10496491.2017.1297979.

[25] L. Scherer et al., "Global priorities of environmental issues to combat food insecurity and biodiversity loss," Sci. Total Environ., vol. 730, 2020, doi: 10.1016/j.scitotenv.2020.139096.

[26] S.H. Raza, A.A. Adamu, E.C. Ogadimma, and A. Hasnain, "The Influences of Political Values Manifested in Advertisements on Political Participation: Moderating Roles of Self-transcendence and Conservation," $J$. Creat. Commun., vol. 15, no. 3, pp. 318-341,
Nov. 2020, doi: 10.1177/0973258620952919.

[27] R.J. House, N.R. Quigley, and M. S. de Luque, "Insights from project globe: Extending global advertising research through a contemporary framework," Int. J. Advert., vol. 29, no. 1, 2010, doi: 10.2501/S0265048709201051.

[28] R. Terlutter, S. Diehl, and B. Mueller, The cultural dimension of assertiveness in crosscultural advertising: The perception and evaluation of assertive advertising appeals, vol. 29, no. 3. 2010.

[29] . N.S. Rahimi, B. Mohamad, T. Alhaiou, \& S.H. Raza, S.H. (2019). "Determinants of Attitudes towards Web Advertising: An Evidence from Malaysia", Jurnal The Messenger, vol 11, np. 1A, 2019 